\title{
Diagnostic Performance of Erythropoietin and Erythropoietin Receptors Levels in Children with Attention Deficit Hyperactivity Disorder
}

\author{
Meltem Gungor ${ }^{1}$, Ergul Belge Kurutas ${ }^{2}$, Erkan Oner $^{3}$, Velid Unsal ${ }^{4}$, Hatice Altun ${ }^{5}$, Ali Erdinc Yalin ${ }^{3}$, \\ Serap Yalin ${ }^{3}$, Ozlem Bozkus', Nilfer Sahin ${ }^{6}$ \\ ${ }^{1}$ Department of Medical Biochemistry, Faculty of Medicine, Sanko University, Gaziantep, ${ }^{2}$ Department of Medical Biochemistry, Faculty of \\ Medicine, Sutcu Imam University, Kahramanmaras, ${ }^{3}$ Department of Biochemistry, Faculty of Pharmacy, Mersin University, Mersin, ${ }^{4}$ Faculty of \\ Health Sciences and Central Research Laboratory, Mardin Artuklu University, Mardin, ${ }^{5}$ Department of Child and Adolescent Psychiatry, Faculty \\ of Medicine, Sutcu Imam University, Kahramanmaras, ${ }^{6}$ Department of Child and Adolescent Psychiatry, Faculty of Medicine, Sitki Koçman \\ University, Mugla, Turkey
}

\begin{abstract}
Objective: Attention deficit hyperactivity disorder (ADHD) is a heterogeneous, highly heritable, a common childhood neurobehavioural disorder resulting from complex gene-gene and gene-environment interactions. The erythropoietin (Epo)/erythropoietin receptors (EpoR) system turned out to have additional important functions in nonhematopoietic tissue. In this study, we aimed to investigate the levels of Epo and and EpoR, and also their diagnostic values in children with ADHD.

Methods: A total of 70 children were included in the study, 35 drug-naive patients with ADHD (age: 6-12 years; male/female: 20/15) and 35 healthy controls (age: 6-12 years; male/female: 22/13). Serum Epo and EpoR levels was determined using a commercial sandwich enzyme-linked immunosorbent assay kit.

Results: The results indicated that the levels of Epo decreased in patients with ADHD compared to control $(p<0.05)$. On the other hand, EpoR levels increased in these patients $(p<0.05)$. Furthermore, the ratio of Epo/EpoR was significantly lower in ADHD patients than controls $(p<0.05)$. Receiver operator characteristic curve analysis showed high diagnostic performance for Epo and EpoR, areas under curve were 0.980 and 1.000, respectively.

Conclusion: This is the first report to investigate the association between serum Epo and EpoR levels in ADHD patients. Our results indicated that Epo may play a role in the etiology of ADHD, and Epo therapy may be beneficial in these disorders if given in addition to the routine treatment of children with ADHD. Furthermore, our results reveal possible diagnostic value of Epo and EpoR.
\end{abstract}

KEY WORDS: Attention deficit hyperactivity disorder; Erythropoietin; Erythropoietin receptors.

\section{INTRODUCTION}

Attention deficit hyperactivity disorder (ADHD) is a multifactorial and clinically heterogeneous disorder that is associated with tremendous financial burden, stress to families, and adverse academic and vocational outcomes

Received: July 20, 2020 / Revised: October 4, 2020

Accepted: November 5, 2020

Address for correspondence: Ergul Belge Kurutas

Department of Medical Biochemistry, Faculty of Medicine, Sutcu Imam University, Avsar ST. No: 251/A, 46100 Kahramanmaras, Turkey

E-mail: ergulkurutas@gmail.com

ORCID: https://orcid.org/0000-0002-6653-4801
[1]. ADHD prevalence has been estimated at 5.0-7.1\% in children and adolescents worldwide $[2,3]$. ADHD is diagnosed more frequently in males than in females [4]. Prospective studies spanning over 30 years have noted the highly impairing consequences of ADHD. Diagnosis in childhood is associated with poor educational, occupational, economic, and social outcomes, as well as higher criminality in adulthood [5,6]. The etiology of ADHD has not been clearly identified, although evidence supports neurobiologic and genetic origins [7]. Structural and functional imaging studies suggest that dysfunction in the fronto-subcortical pathways, as well as imbalances in the dopaminergic and noradrenergic systems, contribute to

(ㄷ) This is an Open-Access article distributed under the terms of the Creative Commons Attribution Non-Commercial License (http://creativecommons.org/licenses/by-nc/4.0) which permits unrestricted non-commercial use, distribution, and reproduction in any medium, provided the original work is properly cited. 
the pathophysiology of ADHD [8].

Erythropoietin (Epo) is an acidic glycoprotein hormone that is produced by the kidney and to a much lesser degree $(<10$ percent) the liver. Epo binds to transmembrane erythropoietin receptor (EpoR), which are expressed primarily by hematopoietic progenitor cells but also by nonhematopoietic cells and tissues such as endothelial cells, cardiomyocytes, and neurons, the liver, uterus, and retina [9]. It was showed that Epo has a neuroprotective and neurotrophic effects in animal models. Also, Epo has trophic effects on dopaminergic neurons [10]. In vitro evidence established that EpoR promotes the growth, differentiation, and function of cultured dopaminergic cells. Under hypoxic culture conditions, neural progenitors differentiate toward a dopaminergic phenotype, EpoR promotes their survival and differentiation, and these effects are blocked by anti-Epo antibodies [11]. Epo also stimulates striatal dopamine release. Exposure to hypoxia-ischemia alters dopamine receptor and dopamine uptake transporter expression. During development, mesencephalic dopamine neurons exhibit apoptosis that is blocked by $\mathrm{Bcl}-2$ upregulation [12]. As a neuroprotective agent Epo has many functions: antagonizing glutamate cytotoxic action, enhancing antioxidant enzyme expression, reducing free radical production rate, and affecting neurotransmitter release. It exerts its neuroprotective effect indirectly through restoration of blood flow or directly by activating transmitter molecules in neurons that also play a role in erythrogenesis.

Oxidative stress significantly impacts multiple cellular pathways that can lead to the initiation and progression of varied disorders throughout the body [13]. Epo controls a variety of signal transduction pathways during oxidative stress. The role of Epo and EpoR in psychiatric disorders are still poorly understood.

Biomarkers could potentially identify clinically meaningful subgroups within highly heterogeneous populations and thus allow for more precise, individualized medical care by identifying risk, confirming diagnosis or guiding response to treatments. The diagnosis of $A D H D$ is made with subjective criterias according to Diagnostic and Statistical Manual of Mental Disorders, 5th edition (DSM-5). The objective markers are yet had not identified for the diagnosis of psychiatric diseases. The diagnostic value of peripheral biomarkers is more important than other biomarkers because their collection and use is easy and suitable in clinical practice. Previously a groving body of research determined inflamation [14] oxidative parameters [15] and etc. as biomarkers in psychiatric diseases. There is no information on diagnostic values of Epo and EpoR in ADHD.

\section{METHODS}

\section{Participants}

This prospective study was approved by the Kahramanmaras Sutcu Imam University ethical committee (Date: 14.12.2018, Decision Number: 2018/312-6), and written informed consent was obtained from all subjects. The study included 35 (20 boys, 15 girls) newly diagnosed drug-naive children with ADHD aged 6-12 years and a control group of 35 (22 boys, 13 girls) age and sex-matched healthy children. The diagnosis of ADHD was reached based on a clinical interview and using the DSM-5 [7]. To support the diagnosis of ADHD and exclude comorbid psychiatric disorders, the Schedule for Affective Disorders and Schizophrenia for School-Age Children-Present and Lifetime Version (K-SADS-PL) was applied [16]. The K-SADS-PL is a semi-structured interview, and the version adapted for the Turkish population [17] was used in this study. Patients in ADHD group did not take any medication 6 weeks prior to the study. Patients with comorbid psychiatric disorders, genetic syndromes, metabolic disorders, neurological disease and obesity were excluded from the study. Children without known neurodevelopmental/neurological disorders, without physical and psychiatric disorders, non-obesity and who had not been on any medication were selected for the control group. The children in the patient and control groups were fed a normal diet and their body mass index (BMI) was within normal limits. Medical illnesses in both groups were excluded based on the patient medical history, clinical examinations, and routine laboratory tests (biochemical, hematological, and thyroid function tests). The intelligence quotient (IQ) was determined using Wechsler Intelligence Scale for Children-Revised, and children with an IQ score greater than 80 were included in the study. The parents of the children were given the Conners' Parent Rating Scale-Revised Long Form [18], and the teachers of children from both groups completed the Conners' Teacher Rating Scale [19-21]. 


\section{Biochemical Analysis}

All blood samples were taken from both groups between 7:30 a.m. to 17:00 p.m, because diurnal variation of Epo or EpoR have been reported in literature [14]. Then, the serum was promptly separated, in a refrigerated centrifuge, and stored at $-20^{\circ} \mathrm{C}$ until analysis. Epo and EpoR levels in serum were measured with in vitro enzyme-linked immunosorbent assay.

\section{Statistical Analysis}

Statistical analysis was performed using the SPSS ver. 11.5 (SPSS Inc., Chicago, IL, USA) and MedCalc ${ }^{\circledR}$ ver. 11.0.1 (MedCalc Software Ltd, Ostend, Belgium). A $p$ value of less than 0.05 was considered statistically significant. The normality of continuous variables was assessed using Shapiro-Wilk's W-test. Relationships between the categorical variables were evaluated using the chi-square test. To compare of mean differences for normally distributed continuous variables between the two groups, a Student's $t$ test was used. The Mann - Whitney $U$ test was used to

Table 1. Sociodemographic characteristics of the study groups

\begin{tabular}{lccc}
\hline Variable & ADHD group & Control group & $p$ value \\
\hline Age $(\mathrm{yr})$ & $8.83 \pm 2.99$ & $8.61 \pm 2.93$ & 0.21 \\
Sex & & & 0.43 \\
Male & $20(57.14)$ & $22(62.85)$ & \\
Female & $15(42.85)$ & $13(37.14)$ & \\
BMI $(\mathrm{kg} / \mathrm{m})$ & $18.34 \pm 2.57$ & $17.95 \pm 3.89$ & 0.86 \\
\hline
\end{tabular}

Values are presented as mean \pm standard deviation or number (\%). ADHD, attention deficit hyperactivity disorder; BMI, body mass index. No significant differences between $\mathrm{ADHD}$ and control groups according to age, sex, and BMI ( $p>0.05)$.

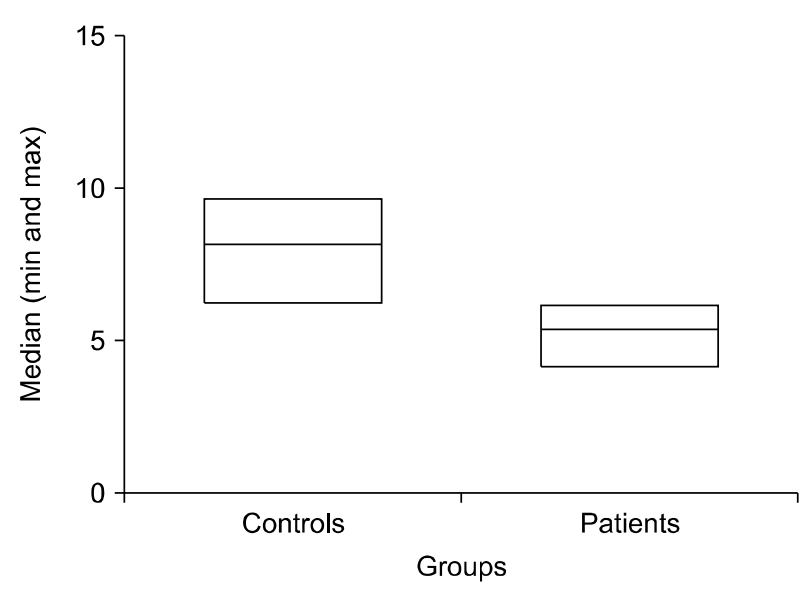

Fig. 1. The levels of erythropoietin in patients and control groups. compare the two groups when the assumption of normality was not fulfilled. While investigating associations of data, correlation coefficients and their significance were calculated with Spearman's test (for non-normally distributed variables) and Pearson's test (for normally distributed variables). A receiver operator characteristics (ROC) curve was plotted in order to find the cut-off point.

\section{RESULTS}

Seventy individuals were included in the study. The mean age of the ADHD group $(n=35)$ was $8.83 \pm 2.99$ years, and $20(57.14 \%)$ were males. The mean age of the control group $(\mathrm{n}=35)$ was $8.61 \pm 2.93$ years, and 22 $(62.85 \%)$ were males. Sociodemographic characteristics are shown in Table 1. No significant differences were found between the groups in terms of age, sex, weight, height, and BMI ( $p>0.05$ for all).

Epo levels were significantly lower in patients than healthy controls (medians were $5.41 \mathrm{mlU} / \mathrm{ml}$ and 8.25 $\mathrm{mIU} / \mathrm{ml}$, respectively, $p<0.001)$. The highest and lowest bounds for Epo in ADHD patients were $6.27 \mathrm{mIU} / \mathrm{ml}$ and $4.09 \mathrm{mIU} / \mathrm{ml}$, respectively. The highest and lowest bounds for Epo in the control group were $9.76 \mathrm{mlU} / \mathrm{ml}$ and 6.15 $\mathrm{mlU} / \mathrm{ml}$, respectively (Fig. 1). EpoR levels were significantly higher in patients than in controls (medians were $1.71 \mathrm{ng} / \mathrm{ml}$ and $0.57 \mathrm{ng} / \mathrm{ml}$ respectively, $p=0.042$ ). The highest and lowest bounds for EpoR in ADHD patients were $1.98 \mathrm{ng} / \mathrm{ml}$ and $1.54 \mathrm{ng} / \mathrm{ml}$, respectively. The highest and lowest bounds for EpoR in the control group were $0.73 \mathrm{ng} / \mathrm{ml}$ and $0.39 \mathrm{ng} / \mathrm{ml}$, respectively (Fig. 2). Further-

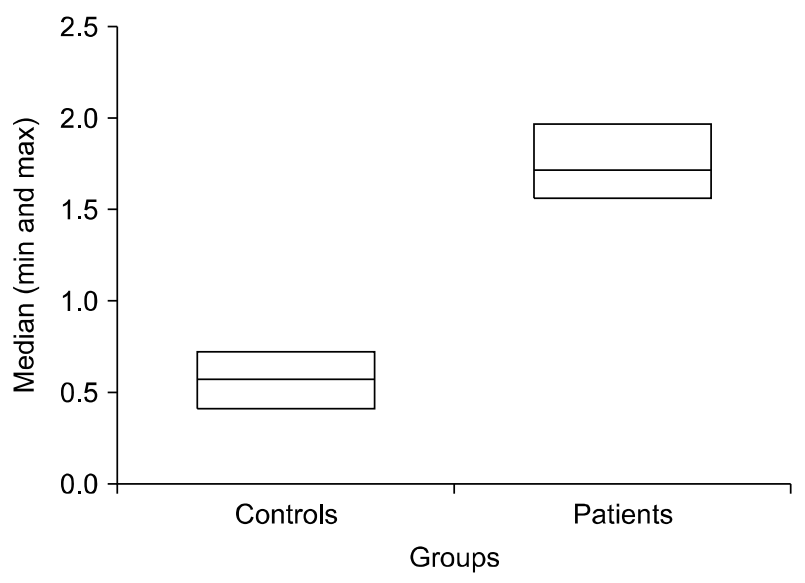

Fig. 2. The levels of erythropoietin receptor in patients and control groups. 
more, the ratio of Epo/EpoR was significantly lower in ADHD patients than controls ( $p<0.05$ ) (Fig. 3).

The lower serum Epo levels corresponded to higher ADHD scores. The Epo levels were negatively correlated with the hyperactivity, Clinical Global Impression-irritabilityimpulsivity, ADHD index, DSM-IV inattentiveness and hyperactivity, and the total scores of the Conners' Parent Rating Scale-Revised Long Form, as well as with the inattentiveness, hyperactivity and conduct sub-scores of the Conners' Teacher Rating Scale $(p<0.05)$. On the contrary, positive significant correlation was observed between EpoR levels and in all scales $(p<0.05)$ (Table 2).

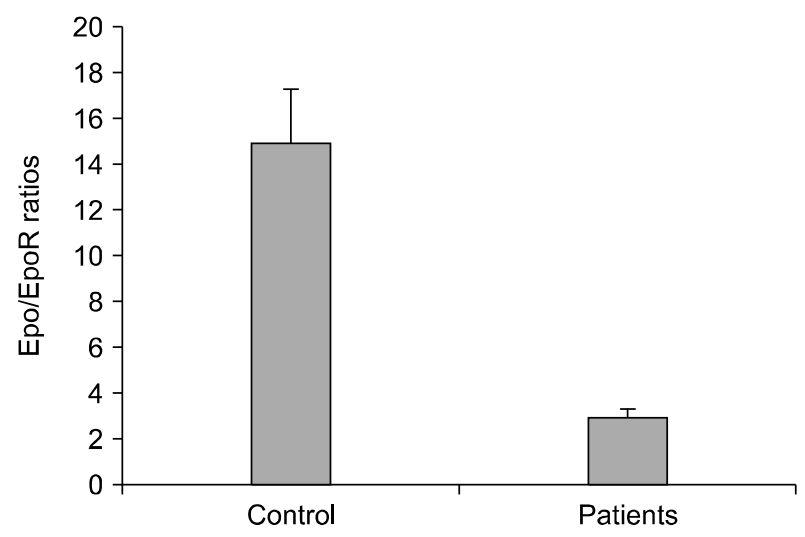

Fig. 3. Erythropoietin (Epo)/erythropoietin receptor (EpoR) ratios in control and patients groups.
A ROC curve was plotted for Epo and EpoR levels. Areas under the curve were 0.980 for Epo $(p<0.001)$, and 1.000 for EpoR $(p<0.001)$. These findings indicate that Epo and EpoR levels are diagnostic. The cut-off point was $6.27 \mathrm{mlU} / \mathrm{ml}$ for Epo, and all of the patient group Epo levels were under the cut-off point. The sensitivity and specificity of Epo were $100 \%$ and $97.14 \%$, repectively. For EpoR, the cut-off point was $0.73 \mathrm{ng} / \mathrm{ml}$, and all of the patient group EpoR levels were above the cut-off point. The sensitivity and specificity of EpoR were $100 \%$ (Fig. 4).

\section{DISCUSSION}

To our knowledge, this is the first study examining the levels of Epo and EpoR in children with ADHD. We found that the levels of Epo in patients with ADHD were lower than the controls. However, EpoR levels were increased in these patients. This situation may be due to decreased neuronal function. We thought that EpoR may be a good choice for ADHD treatment. Furthermore, in our study, decreased levels of Epo/EpoR ratio may due to low Epo levels. Until now, Epo/EpoR ratio has not been reported in patients with ADHD. So, we did not compared to our results. We thought that decreased Epo/EpoR ratio may be an important biochemical biomarker for ADHD.

Many studies showed that total oxidant status (TOS)

Table 2. Relationship of Epo and EpoR levels in patients and control groups with the Conners' Parent and Teacher Rating Scale Scores

\begin{tabular}{|c|c|c|c|c|}
\hline \multirow{2}{*}{ Scale parameters } & \multicolumn{2}{|c|}{ Epo } & \multicolumn{2}{|c|}{ EpoR } \\
\hline & $r$ & $p$ & r & $p$ \\
\hline \multicolumn{5}{|c|}{ Conners' Parent Rating Scale-Revised } \\
\hline Oppositional & 0.233 & 0.26 & -0.243 & 0.35 \\
\hline Hyperactivity & 0.155 & $0.01 *$ & -0.107 & $0.01^{*}$ \\
\hline Anxiety-Shy & 0.708 & 0.65 & 0.564 & 0.24 \\
\hline Social problems & 0.249 & 0.31 & -0.238 & 0.35 \\
\hline Psychosomatic & 0.228 & 0.48 & -0.355 & 0.42 \\
\hline ADHD index & 0.267 & $0.01^{*}$ & 0.246 & $0.02 *$ \\
\hline DSM-IV inattentivenes & 0.107 & $0.04^{*}$ & -0.467 & $0.01^{*}$ \\
\hline DSM-IV hyperactivity & 0.113 & $0.01^{*}$ & 0.125 & $0.03^{*}$ \\
\hline DSM-IV total & 0.176 & $0.02 *$ & -0.344 & $0.01 *$ \\
\hline CGl-irritability-impulsivity & 0.208 & $0.03 *$ & -0.133 & $0.04 *$ \\
\hline CGI-emotional lability & 0.188 & 0.53 & -0.177 & 0.42 \\
\hline \multicolumn{5}{|c|}{ Conners' Teacher Rating Scale-Revised } \\
\hline Inattentivenes & 0.345 & $0.04 *$ & -0.423 & $0.02 *$ \\
\hline Hyperactivity & 0.309 & $0.02 *$ & -0.338 & $0.03^{*}$ \\
\hline Conduct problems & 0.364 & $0.03^{*}$ & -0.346 & $0.02 *$ \\
\hline
\end{tabular}

Epo, erythropoietin; EpoR, erythropoietin receptor; ADHD, attention deficit hyperactivity disorder; DSM-IV, the Diagnostic and Statistical Manual of Mental Disorders 4th edition; CGI, Clinical Global Impression.

*Significant differences amongs Epo and EpoR levels with the Conners' Parent and Teacher Rating Scale Scores $(p<0.05)$. 

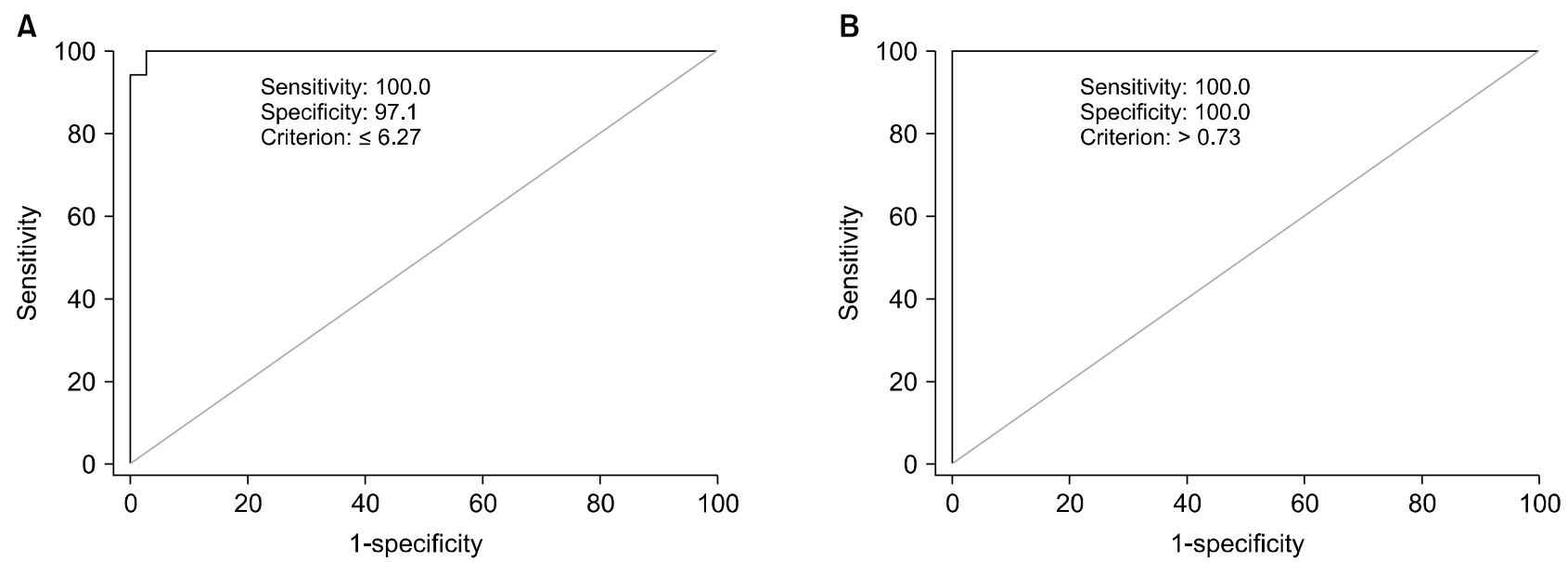

Fig. 4. (A) Receiver operator characteristics (ROC) curve of erythropoietin. (B) ROC curve of erythropoietin receptor.

and oxidative stress index (OSI) values are higher than controls in before treatment individuals with ADHD, thiol is one of the most important components of total antioxidant capacity in plasma that is lower than controls, these were found in a study where before and after medication to oxidative metabolism in adolescents and children with ADHD was evaluated. Levels of antioxidant parameters after treatment are higher than before treatment and OSI values in after treatment are lower than before treatment in the same study [22]. Also, there are studies showing that malondialdehyde (MDA) is an indicator of lipid peroxidation, levels of MDA are high in individuals with ADHD [23], but there are also studies with conflicting results [24].

In our study, we say that these changes of Epo and EpoR levels may relation to oxidative status of patients with ADHD. We thought that elevated oxidative stress and decreased Epo response may be associated with the decreased neuronal function in ADHD. We think that EpoR may act as an Epo "buffer" regulating available circulating Epo concentration. A lower Epo concentration, may increase unbound free plasma EpoR and, therefore, its availability for binding EpoR.

Many studies reported that neural tube defects developed and neuroblasts migration affected suppressed Epo and EpoR genes in mouse embryos [25]. In addition, it has been shown that the reduction of precursor neuronal cells and increased apoptosis with brain development is impaired [26]. Epo, activates to Janus kinase 2 via EpoR and it has function neuronal survival with preservation [27]. Epo and EpoR increase after trauma, lower in intact neu- rons and glial cells it has been shown in many studies [28]. Studies demonstrate that Epo reduced dorsal root ganglion apoptosis, supports recovery of mechanical allodynia after peripheral nerve injury and Epo may also be effective in treating neuropathic pain [29]. However some studies have been shown, Epo just doesn't have the antiapoptotic properties of putative neuroprotective agents at the same time it protects against axonal degeneration [30]. Spinal cord injury in study demonstrates that traumatic neutrophil infiltration and decreased at the 24th hour significantly increased myeloperoxidase level, decreased caspase-3 enzyme activity in Epo applied after trauma groups [31]. We said that the biological effects of Epo may not always be beneficial and may be poorly tolerated in a number of clinical scenarios, necessitating further basic and clinical investigations that emphasize the elucidation of the signal transduction pathways controlled by Epo to direct both successful and safe clinical care.

High correlation values constitute an important part of our findings. The correlation coefficient is shown with the ' $r$ ' symbol. An $r$ value $\leq 0.35$ represents low or weak correlation, between 0.36 and 0.67 shows moderate correlation, 0.68 to 0.90 shows high correlation, and 0.90 to 1.0 shows very high correlation [32]. We found that a significant negative correlation between ADHD scores and Epo levels. However, we found that a positive correlation between ADHD scores and EpoR levels. There are no studies between Epo and ADHD scores, or between EpoR and ADHD scores in patients with ADHD. So, we did not compared to our results. We believe that a high correla- 
tion coefficient forms a basis for the detection of biomarkers.

ADHD is associated with a significant deterioration in various areas of functioning, including social and peer functioning, academic achievement, as well as emotional and cognitive functions. In a meta-analysis of 83 studies, Willcutt et al. [33] showed that, compared to children without ADHD, children/adolescents with ADHD demonstrate significant deficits in measures of executive functions, such as response inhibition, vigilance, working memory and planning. Low serum Epo levels observed in our ADHD group indicate that the role of Epo in the development of neurocognitive deficits in ADHD should be further investigated.

To the best of our knowledge, our study is the first study investigating the diagnostic value of Epo and EpoR parameters with a ROC curve in ADHD. In ROC curve analysis, diagnostic accuracy is measured according to the area under the curve $(A \cup C)$. The accuracy of the ROC-AUC test is as follows: 0.9 to 1 , excellent; 0.8 to 0.9 , good; 0.7 to 0.8 , fair; 0.6 to 0.7, poor; and $<0.6$, not useful [33]. The AUCs for Epo and EpoR were 0.98 and 1.0, respectively. Epo and EpoR levels represent excellent diagnostic value according to our results. As far as we know, there are no studies evaluating the diagnostic potential of Epo and EpoR. Therefore, we cannot compare these results. Although our results show excellent diagnostic value, we do not interpret these data as a discovery of new biomarkers.

Our results support the concept that a dynamic EpoEpoR signaling system is present in the ADHD and may offer a new therapeutic modality for ADHD. A number of drugs are used in the treatment of ADHD. These drugs which dysregulated dopaminergic pathways may interfere with normal development in children and deteriorate the functions of neurons in adults with ADHD. It has been demonstrated that methylphenidate treatment increases extracellular dopamine levels in ADHD [10-12]. Therefore, the medications used for the treatment of ADHD as a factor which may be related or alter the results obtained of Epo and EpoR. Thus, further studies are needed in children receiving treatment for $\mathrm{ADHD}$ and it will be possible to see the effects of the drugs used on Epo and EpoR. Moreover, increasing understanding of the Epo and EpoR cellular and tissue distribution, as well as its function in ADHD, may contribute to the development of new diagnostic and prognostic approaches and customized treat- ment modalities.

The limitations of this study include the small sample size and its cross-sectional design. Also, the results obtained with serum Epo and EpoR levels may not completely reflect the brain levels of Epo and EpoR in children with ADHD. Thus, in vitro or in vivo studies are required to gain more insight into the brain levels of Epo and EpoR and to be considered as a potential biomarker. On the other hand, the major strength of our study is that, as far as we know, this is the first report on serum Epo and EpoR levels in children with ADHD. Additional large-scale studies are needed to clarify the regulatory mechanisms of Epo and EpoR in ADHD.

\section{Conflicts of Interest}

No potential conflict of interest relevant to this article was reported.

\section{Author Contributions}

Conceptualization: Meltem Gungor, Ergul Belge Kurutas. Data acquisition: Meltem Gungor, Ergul Belge Kurutas, Hatice Altun, Ozlem Bozkus, Nilfer Sahin. Formal analysis: Erkan Oner, Hatice Altun, Ozlem Bozkus, Nilfer Sahin. Supervision: Meltem Gungor, Ergul Belge Kurutas, Velid Unsal, Hatice Altun, Ali Erdinc Yalin, Serap Yalin. Writing-original draft: Meltem Gungor, Ergul Belge Kurutas. Writing-review \& editing: Meltem Gungor, Ergul Belge Kurutas.

\section{ORCID}

Meltem Gungor https://orcid.org/0000-0002-8062-1610

Ergul Belge Kurutas https://orcid.org/0000-0002-6653-4801

Erkan Oner https://orcid.org/0000-0002-6332-6484

Velid Unsal https://orcid.org/0000-0003-1415-0563

Hatice Altun https://orcid.org/0000-0002-6802-8216

Ali Erdinc Yalin https://orcid.org/0000-0002-3351-6885

Serap Yalin https://orcid.org/0000-0002-1286-2172

Ozlem Bozkus https://orcid.org/0000-0003-1269-1008

Nilfer Sahin https://orcid.org/0000-0001-7120-1561

\section{REFERENCES}

1. Biederman J. Attention-deficit/hyperactivity disorder: a selective overview. Biol Psychiatry 2005;57:1215-1220.

2. Polanczyk G, de Lima MS, Horta BL, Biederman J, Rohde LA. The worldwide prevalence of ADHD: a systematic review and metaregression analysis. Am J Psychiatry 2007; 164:942- 948.

3. Willcutt EG. The prevalence of DSM-IV attention-deficit/hyper- 
activity disorder: a meta-analytic review. Neurotherapeutics 2012;9:490-499.

4. Davies W. Sex differences in attention deficit hyperactivity disorder: candidate genetic and endocrine mechanisms. Front Neuroendocrinol 2014;35:331-346.

5. Klein RG, Mannuzza S, Olazagasti MA, Roizen E, Hutchison JA, Lashua EC, et al. Clinical and functional outcome of childhood attention-deficit/hyperactivity disorder 33 years later. Arch Gen Psychiatry 2012;69:1295-1303.

6. Satterfield JH, Faller KJ, Crinella FM, Schell AM, Swanson JM, Homer LD. A 30-year prospective follow-up study of hyperactive boys with conduct problems: adult criminality. I Am Acad Child Adolesc Psychiatry 2007;46:601-610.

7. American Psychiatric Association. Diagnostic and statistical manual of mental disorders: DSM-5. 5th ed. Washington, D.C.:American Psychiatric Publishing;2013.

8. Gallo EF, Posner J. Moving towards causality in attention-deficit hyperactivity disorder: overview of neural and genetic mechanisms. Lancet Psychiatry 2016;3:555-567.

9. Polanczyk GV, Casella EB, Miguel EC, Reed UC. Attention deficit disorder/hyperactivity: a scientific overview. Clinics (Sao Paulo) 2012;67:1125-1126.

10. Quintero J, Navas M, Fernández A, Ortiz T. Advances in attention deficit hyperactivity disorder. What does neuroimaging provide us with? Actas Esp Psiquiatr 2009;37:352-358.

11. McPherson RJ, Juul SE. Recent trends in erythropoietin-mediated neuroprotection. Int I Dev Neurosci 2008;26:103-111.

12. Meng SZ, Ohyu J, Itoh M, Takashima S. Dopamine transporter and nitric oxide synthase in hypoxic-ischemic brain. Pediatr Neurol 2000;22:115-121.

13. Kurutas EB. The importance of antioxidants which play the role in cellular response against oxidative/nitrosative stress. current state. Nutr J 2016;15:71.

14. Howren MB, Lamkin DM, Suls J. Associations of depression with C-reactive protein, IL-1, and IL-6: a meta-analysis. Psychosom Med 2009;71:171-186.

15. Findıklı E, Camkurt MA, İzci F, Karaaslan MF, Fındıklı HA, Sümer $\mathrm{P}$, et al. The diagnostic value of malondialdehyde, superoxide dismutase and catalase activity in drug naive, first episode, non-smoker generalized anxiety disorder patients. Clin Psychopharmacol Neurosci 2018;16:88-94.

16. Kaufman J, Birmaher B, Brent D, Rao U, Flynn C, Moreci P, et al. Schedule for affective disorders and schizophrenia for school-age children-present and lifetime version (K-SADS-PL): initial reliability and validity data. I Am Acad Child AdolesC Psychiatry 1997;36:980-988.

17. Gökler B, Ünal F, Pehlivantürk B, Kültür EÇ, Akdemir D, Taner $\mathrm{Y}$. [Reliability and Validity of schedule for affective disorders and schizophrenia for school age children--present and lifetime version-Turkish version (K-SADS-PL-T)]. Turk J Child Adolesc Ment Health 2004;11:109-116. Turkish.

18. Conners CK. Conners' rating scales-revised: user's manual.
North Tonawanda:Multi-Health Systems;1997.

19. Goyette $\mathrm{CH}$, Conners $\mathrm{CK}$, Ulrich RF. Normative data on revised Conners parent and teacher rating scales. I Abnorm Child Psychol 1978;6:221-236.

20. Dereboy C, Senol S, Sener S, Dereboy F. /Validation of the Turkish versions of the short-form Conners' teacher and parent rating scales]. Turk Psikiyatri Derg 2007;18:48-58. Turkish.

21. Şener Ş, Dereboy Ç, Dereboy İF, Sertcan Y. Conners' teacher rating scale Turkish version-I. J Child Youth Ment Health 1995;2:131-141. Turkish.

22. Guney $\mathrm{E}$, Cetin $\mathrm{FH}$, Alisik M, Tunca $\mathrm{H}$, Tas Torun $\mathrm{Y}$, Iseri $\mathrm{E}$, et al. Attention deficit hyperactivity disorder and oxidative stress: a short term follow up study. Psychiatry Res 2015;229: 310-317.

23. Bulut M, Selek S, Bez Y, Cemal Kaya M, Gunes M, Karababa $\mathrm{F}$, et al. Lipid peroxidation markers in adult attention deficit hyperactivity disorder: new findings for oxidative stress. Psychiatry Res 2013;209:638-642.

24. Oztop D, Altun H, Baskol G, Ozsoy S. Oxidative stress in children with attention deficit hyperactivity disorder. Clin Biochem 2012;45:745-748.

25. Tsai PT, Ohab JJ, Kertesz N, Groszer M, Matter C, Gao J, et al. A critical role of erythropoietin receptor in neurogenesis and post-stroke recovery. J Neurosci 2006;26:1269-1274.

26. Savino R, Ciliberto G. A paradigm shift for erythropoietin: no longer a specialized growth factor, but rather an all-purpose tissue-protective agent. Cell Death Differ 2004;11 Supp/ 1: S2-S4.

27. Tong W, Zhang J, Lodish HF. Lnk inhibits erythropoiesis and Epo-dependent JAK2 activation and downstream signaling pathways. Blood 2005;105:4604-4612.

28. Sirén AL, Knerlich F, Poser W, Gleiter CH, Brück W, Ehrenreich $\mathrm{H}$. Erythropoietin and erythropoietin receptor in human ischemic/hypoxic brain. Acta Neuropathol 2001;101:271-276.

29. Campana WM, Myers RR. Exogenous erythropoietin protects against dorsal root ganglion apoptosis and pain following peripheral nerve injury. Eur J Neurosci 2003;18:1497-1506.

30. Keswani SC, Buldanlioglu U, Fischer A, Reed N, Polley M, Liang $\mathrm{H}$, et al. A novel endogenous erythropoietin mediated pathway prevents axonal degeneration. Ann Neurol 2004;56: 815-826.

31. Okutan O, Solaroglu I, Beskonakli E, Taskin Y. Recombinant human erythropoietin decreases myeloperoxidase and caspase-3 activity and improves early functional results after spinal cord injury in rats. J Clin Neurosci 2007; 14:364-368.

32. Taylor R. Interpretation of the correlation coefficient: a basic review. J Diagn Med Sonogr 1990;6:35-39.

33. Willcutt EG, Doyle AE, Nigg JT, Faraone SV, Pennington BF. Validity of the executive function theory of attention-deficit/ hyperactivity disorder: a meta-analytic review. Biol Psychiatry 2005; 57:1336-1346. 